JRPB, Vol. 7, No. 2, September 2019, Hal. 148-156

DOI: $10.29303 / \mathrm{jrpb} . v 7 \mathrm{i} 2.113$

ISSN 2301-8119, e-ISSN 2443-1354

Tersedia online di http://jrpb.unram.ac.id/

\title{
RANCANGBANGUN MESIN PRODUKSI ASAP CAIR DARI TEMPURUNG KELAPA BERBASIS TEKNOLOGI CYCLONE-REDISTILLATION
}

\author{
Design of Coconut Shell Liquid Smoke Production Machine Based on \\ Cyclone-Redistillation Technology
}

\section{Muhammad Fathussalam $^{1}$, Angky Wahyu Putranto ${ }^{1 *)}$, Bambang Dwi Argo ${ }^{1}$, Arta Harianti $^{1}$, Arsyika Oktaviani ${ }^{2}$, Firda Pramesti Puspaningarum ${ }^{2}$, Sellyan Lorenza Olanda Putri ${ }^{2}$}

\author{
${ }^{1}$ Jurusan Keteknikan Pertanian, Fakultas Teknologi Pertanian, Universitas Brawijaya, Jl. \\ Veteran Malang 65145 \\ ${ }^{2}$ Jurusan Teknologi Industri Pertanian, Fakultas Teknologi Pertanian, Universitas Brawijaya, Jl. \\ Veteran Malang 65145 \\ Email ${ }^{*}$ : angkywahyu@ub.ac.id \\ Diterima: Juli 2019 \\ Disetujui: September 2019
}

\begin{abstract}
The higher of coconut crop production in Indonesia has positively correlated with the amount of coconut shell waste produced which is difficult to decompose by microorganisms. Therefore, the utilization of coconut shell waste into charcoal and liquid smoke has been carried out in recent years. During this time, the conventional process of coconut shell-liquid smoke (CS-LS) takes 3-5 days and produces grade C liquid smoke in low volume. Hence, this study aims to design CS-LS production machine based on cyclone-redistillation technology which which can increase the volume of liquid smoke produced. In this study, the method used was engineering includes structural and functional design also testing performance both apparatus and product. The performance of CS-LS production machine was analyzed by volume for each grades (grade A, B and C). The result showed that CS-LS production machine based on cyclone-redistillation has been production according to specifications, with the total dimension of machine was $132 \mathrm{~cm}$ length, $100 \mathrm{~cm}$ width and $145 \mathrm{~cm}$ height. The volume of grade A CS-LS production was $65 \mathrm{~L}$, whereas the grade B and C volumes was $10 \mathrm{~L}$ and 25 L, respectively, with a shorter total production time than conventional methods in SMEs. Therefore, design of CS-LS production machine based on cycloneredistillation technology has great potentially applied in SMEs for producing liquid smoke in Indonesia to increase productivity and quality of CS-LS.
\end{abstract}

Keywords: design, liquid smoke, coconut shell, cyclone-redistillation, volume 


\begin{abstract}
ABSTRAK
Tingginya produksi tanaman kelapa di Indonesia mempunyai hubungan yang postif dengan jumlah limbah tempurung kelapa yang dihasilkan, dimana limbah tersebut cukup sulit diuraikan oleh mikroorganisme. Oleh karena itu pemanfaatan limbah tempurung kelapa menjadi arang dan asap cair telah banyak dikembangkan dalam beberapa tahun terakhir. Selama ini, proses pembuatan asap cair dari tempurung kelapa (coconut shell-liquid smoke) dilakukan secara konvensional selama 3-5 hari dengan kualitas asap cair grade $\mathrm{C}$ dan volume asap cair yang rendah. Oleh karena itu tujuan penelitian ini yaitu melakukan rancangbangun mesin pembuat asap cair dari tempurung kelapa berbasis teknologi cyclone-redistillation yang dapat meningkatkan volume dari asap cair yang dihasilkan. Metode yang digunakan dalam penelitian ini adalah metode rekayasa (engineering) meliputi perancangan struktural, fungsional dan pengujian performansi untuk alat dan produk yang dihasilkan. Pengujian performansi mesin dianisis berdasarkan volume dari setiap grade (A, B dan C) yang dihasilkan. Hasil penelitian menunjukkan bahwa mesin pembuat asap cair dari tempurung kelapa berbasis teknologi cyclone-redistillation telah diproduksi sesuai spesifikasi dengan dimensi keseluruhan panjang $132 \mathrm{~cm}$, lebar $100 \mathrm{~cm}$ dan tinggi $145 \mathrm{~cm}$. Volume asap cair grade A sebesar $65 \mathrm{~L}$, sedangkan grade $\mathrm{B}$ dan $\mathrm{C}$ masing-masing memiliki volume $10 \mathrm{~L}$ dan 25 L dengan total waktu produksi yang lebih singkat daripada metode konvensional di UKM. Oleh karena itu, rancangbangun mesin pembuat asap cair dari tempurung kelapa berbasis teknologi cyclone-redistillation ini sangat berpotensi untuk diterapkan pada UKM penghasil asap cair di Indonesia guna meningkatkan produktivitas dan kualitas asap cair dari limbah tempurung kelapa.
\end{abstract}

Kata kunci: rancangbangun, asap cair, tempurung kelapa, cyclone-redistillation, volume

\section{PENDAHULUAN}

\section{Latar Belakang}

Tanaman kelapa merupakan salah satu komoditas perkebunan di Indonesia dengan jumlah produksi pada tahun 2015 sebesar 2,9 juta ton (Ditjenbun, 2017). Tahun 2016, Kabupaten Malang menduduki peringkat ketujuh produksi kelapa di Jawa Timur dengan jumlah produksi sebesar 14.253 ton (BPS, 2016). Hal tersebut berkorelasi positif terhadap jumlah limbah tempurung kelapa yang dihasilkan. Limbah tersebut cukup sulit untuk diuraikan oleh mikroorganisme, walaupun masih tergolong dalam limbah organik. Salah satu pemanfaatan limbah tempurung kelapa yaitu dijadikan bahan baku pembuatan asap cair.

Asap cair merupakan cairan kondensat hasil pirolisis tempurung kelapa yang mengandung senyawa penyusun utama asam, fenol, dan karbonil, sehingga banyak diaplikasikan sebagai pengawet alami pada makanan serta memberikan karakteristik sensori berupa aroma, warna, serta rasa yang khas pada produk pangan (Pranata, 2007; Budijanto dkk, 2008), sebagai anti bakteri yang dapat menghambat aktivitas pertumbuhan $S$. aureus, $P$. aeruginosa, E. coli and C. albican (Zuraida et al., 2011; Kailaku et al., 2017). Penggunaan asap cair juga disesuaikan dengan klasifikasi kualitas asap cair yang terdiri dari 3 grade. Grade $\mathrm{C}$ (grade 3) digunakan sebagai pengawet kayu dan koagulan, grade $\mathrm{B}$ (grade 2) digunakan sebagai antimikroba dan grade A (grade 1) digunakan sebagai pengawet alami makanan (Kailaku et al., 2017). Aplikasi asap cair sebagai pengawet alami produk 
pangan, daging dan ikan juga sangat cocok digunakan sebagai alternatif pengawet alami pengganti formalin atau boraks yang banyak digunakan dan menjadi perhatian khusus pada beberapa tahun terakhir.

Selama ini proses pembuatan asap cair yang ada di UKM pengarangan tempurung kelapa dimulai dari pembakaran tempurung kelapa menggunakan tungku dan penutup sederhana serta membutuhkan waktu 3-5 hari untuk mengarangkan 3 ton tempurung kelapa. Asap cair yang dihasilkan dari 3 ton tempurung kelapa adalah asap cair grade $\mathrm{C}$ dengan kualitas yang masih kurang karena asap hasil pembakaran masih tercampur abu dengan kadar tar yang tinggi. Oleh karena itu dibutuhkan teknologi filtrasi untuk mengatasi permasalahan tersebut dengan menggunakan cyclone separator. Menurut Sakin et al. (2017), cyclone separator memiliki berbagai kegunaan dalam operasi dan proses untuk pemisahan partikel karena strukturnya yang sederhana, dapat dipindahkan, biaya operasi dan perawatan rendah. Selain itu, keuntungan menggunakan cyclone separator daripada filter udara konvensional adalah dapat menghilangkan masalah penyumbatan dan meningkatkan kapasitas filtrasi.

Prinsip kerja cyclone menyebabkan aliran gas berputar dan menghasilkan vortex yang menyebabkan partikel pengotor dan tar pada asap dari ruang pirolisis dapat dipisahkan. Asap yang melewati cyclone kemudian dikondensasi dengan air mengalir dan diteruskan ke proses redistilasi. Setelah itu, asap dari proses redistilasi dikondensasi kembali kemudian dialirkan ke media adsorpsi untuk mendapatkan asap cair dengan kualitas yang baik.

Oleh karena itu, tujuan penelitian ini yaitu untuk melakukan rancang bangun mesin produksi asap cair dari tempurung kelapa berbasis teknologi cyclone-redistillation yang dapat meningkatkan volume asap cair yang dihasilkan.

\section{METODE PENELITIAN}

\section{Alat dan Bahan}

Alat-alat yang digunakan pada penelitian ini antara lain : roll pipa, gerinda, mesin las, keran, pompa air, selang, kompor gas, centrifugal blower. Sedangkan bahan-bahan yang digunakan dalam pelaksanaan penelitian ini diantaranya adalah: tempurung kelapa kering, pipa dan plat stainless stell, zeolite, arang aktif dan air bersih.

\section{Metode}

Metode yang digunakan dalam penelitian ini adalah metode rekayasa (engineering), dimana kegiatan yang dilakukan meliputi perencanaan, perancangan, dan pengujian terhadap performansi mesin sehingga memungkinkan adanya suatu modifikasi.

\section{Perancangan Alat Secara Fungsional}

Alat pembuat asap cair ini memiliki bagian bagian dengan fungsi yang berbeda-beda, yaitu:

- Proses filtrasi asap menggunakan cyclone separator. Proses filtrasi asap menggunakan prinsip cyclone dibantu dengan centrifugal blower dengan memanfaatkan prinsip putaran sentrifugasi, sehingga abu dan tar pada asap hasil pirolisis tempurung kelapa di ruang pembakaran akan dipisahkan. Asap yang memiliki kandungan abu dan tar yang rendah ini nanti akan dilanjutkan untuk melewati proses selanjutnya.

- Tabung distilasi dilengkapi dengan termometer dan water level. Termometer berfungsi untuk mengetahui suhu yang digunakan untuk menguapkan asap cair, sedangkan water level berfungsi untuk 
mengetahui volume asap cair yang belum teruapkan.

- Tabung kondensasi dilengkapi dengan pipa stainless stell dibentuk secara spiral sehingga memiliki luas kontak dengan air yang lebih besar agar proses kondensasi akan lebih maksimal.

- Tabung filtrasi dibuat dengan tabung bersekat berbahan stainless steel dengan absorben berupa zeolit dan arang aktif. Tabung filtrasi asap cair menggunakan bahan stainless stell yang bersifat food grade, sehingga asap cair grade A yang dihasilkan aman untuk digunakan sebagai bahan pengawet makanan.

\section{Perancangan Alat Secara Struktural}

Perancangan struktural dilakukan setelah tahap perancangan secara fungsional. Skema rancangbangun mesin pembuat asap cair dari tempurung kelapa berbasis cyclone-redistillation secara keseluruhan dapat dilihat pada Gambar 1.

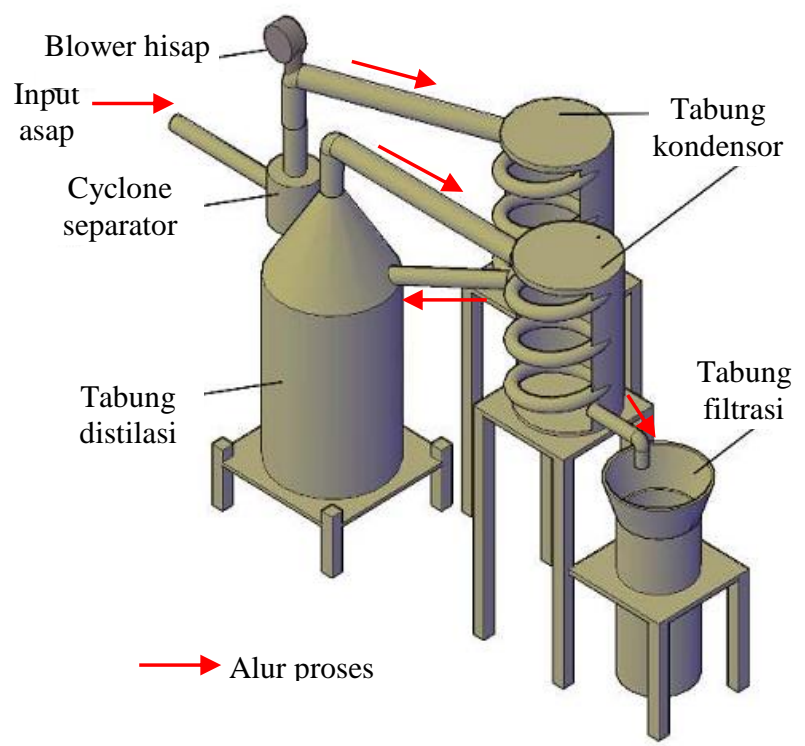

Gambar 1. Skema Rancangbangun Mesin Produksi Asap Cair Berbasis Cyclone-Redistillation

\section{Mekanisme Kerja dan Pengujian Mesin}

Mekanisme sistem kerja mesin pembuat asap cair berbasis teknologi cyclone-redistillation

dalam menghasilkan asap cair grade A, B dan C dapat dilihat pada Gambar 2.

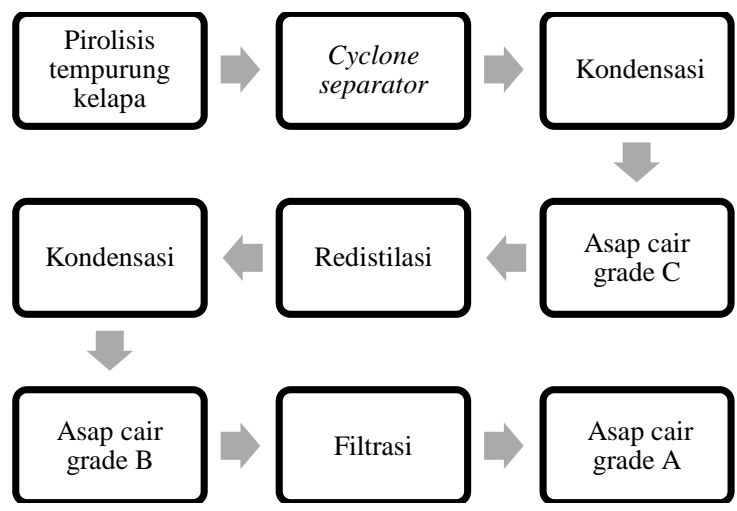

Gambar 2. Mekanisme Sistem Kerja Mesin Pembuat Asap Cair

Pengujian mesin secara fungsional yang dilakukan pada penelitian ini yaitu difokuskan kepada hasil volume asap cair yang dihasilkan yaitu meliputi volume asap cair grade $\mathrm{A}$, grade $\mathrm{B}$ dan grade $\mathrm{C}$. Pengujian ini berfungsi untuk mengetahui berapa kapasitas maksimal asap cair yang dihasilkan. Selain itu waktu proses mesin untuk menghasilkan asap cair juga dibandingkan dengan metode konvensional yang ada di UKM penghasil asap cair di Kabupaten Malang.

\section{HASIL DAN PEMBAHASAN}

\section{Cyclone Separator}

Cyclone separator yang digunakan dalam penelitian ini memiliki tinggi $82 \mathrm{~cm}$ dan diameter $20 \mathrm{~cm}$. Prinsip kerja dari cyclone yaitu memanfaatkan prinsip putaran sentrifugal, dimana partikel udara dialirkan dan berputar pada tabung lingkaran kerucut, sehingga partikel dengan berat jenis lebih besar akan menjauhi titik pusat lingkaran lalu mengalami gaya gravitasi ke bagian bawah kerucut.

Penggunaan teknologi cyclone yang dilengkapi dengan centrifugal blower dengan daya hisap $280 \mathrm{CMH}$ berfungsi untuk memisahkan partikel pengotor dari asap yang keluar dari ruang 
pembakaran (ruang pirolisis). Tersaringnya partikel pengotor seperti debu, tar dan senyawa lain yang berbahaya pada asap, sehingga dapat mengoptimalkan proses kondensasi yang berdampak pada pengingkatan volume asap cair yang dihasilkan. Gambar cyclone separator dapat dilihat pada Gambar 3.
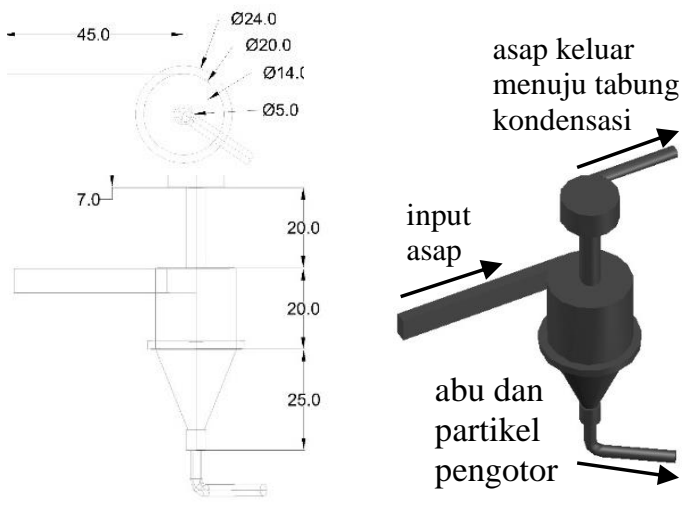

Gambar 3. Cyclone Separator

\section{Tabung Distilasi}

Tabung distilasi merupakan wadah untuk menampung asap cair grade C yang selanjutnya akan dilakukan distilasi untuk menjadi asap cair grade $\mathrm{B}$ dan A. Tabung distilasi dibuat dengan bahan stainless stell dengan tinggi tabung $75 \mathrm{~cm}$ dan diameter $50 \mathrm{~cm}$ serta kerucut dengan tinggi $30 \mathrm{~cm}$ dan diameter $50 \mathrm{~cm}$, sehingga tabung distilasi ini memiliki kapasitas volume maksimum sebesar 100 Liter. Tabung distilasi juga dilengkapi dengan termometer analog yang berfungsi untuk melihat kondisi suhu distilasi yang digunakan yaitu sebesar 90$95^{\circ} \mathrm{C}$. Tabung distilasi juga dilengkapi dengan rangka penyangga dengan tinggi $20 \mathrm{~cm}$ yang berguna untuk ruang penempatan kompor gas. Gambar desain dan realisasi tabung distilasi dapat dilihat pada Gambar 4.
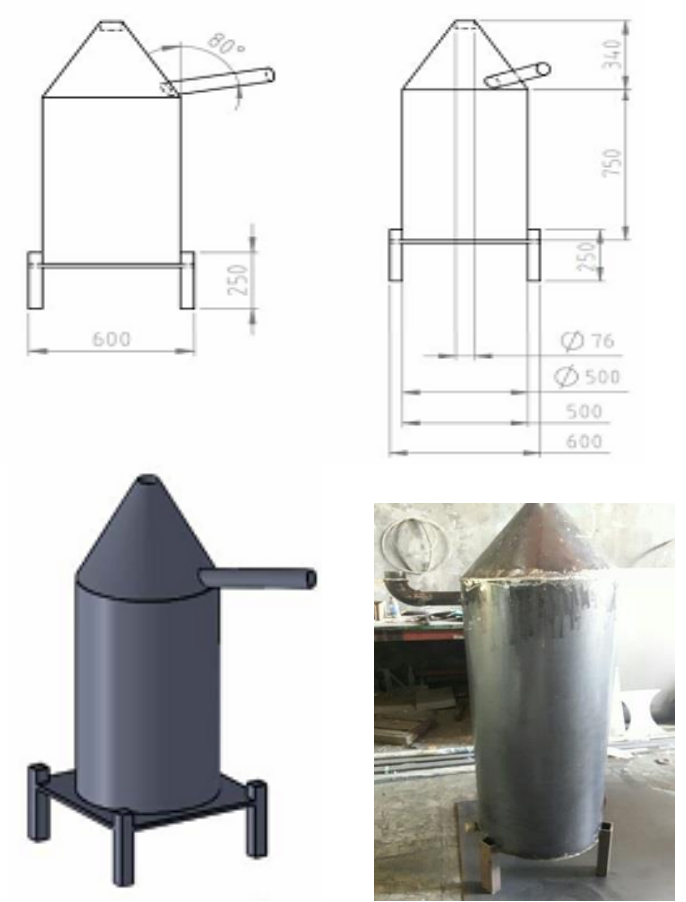

Gambar 4. Tabung Distilasi

Asap cair yang masuk ke dalam tabung distilasi adalah asap cair grade $\mathrm{C}$ yang dihasilkan dari tabung kondensasi pertama. Asap cair grade $\mathrm{C}$ kemudian dilakukan proses redistilasi untuk menurunkan polyaromatic hydrocarbon (PAH) dan tar yang masih terkandung di dalam asap cair. Asap cair yang diuapkan pada tabung distilasi kemudian dikondensasi kembali menuju ke tabung kondensasi kedua.

\section{Tabung Kondensor}

Tabung kondensor yang digunakan pada penelitian ini berjumlah 2 unit dengan dimensi yang sama yaitu memiliki diameter sebesar $40 \mathrm{~cm}$ dan tinggi $60 \mathrm{~cm}$. Pada tabung kondensasi terdapat pipa stainless stell spiral dengan panjang total 14 meter yang dibentuk dalam uliran dengan diameter ulir sebesar $35 \mathrm{~cm}$ serta tinggi $50 \mathrm{~cm}$. Tabung kondensor dapat menampung air sebanyak 70 liter air yang berfungsi untuk merubah asap menjadi fase cair.

Walaupun kedua tabung kondensor didesain dengan dimensi yang sama, namun kedua tabung tersebut 
memiliki fungsi yang berbeda, dimana tabung kondensor pertama yang menghubungan cyclone separator dengan tabung distilasi, yang berfungsi sebagai pendingin balik untuk menghasilkan asap cair grade $\mathrm{C}$. Tabung kondensor kedua yang menghubungkan tabung distilasi dan tabung filtrasi berfungsi sebagai pendingin balik untuk memproduksi asap cair grade $\mathrm{B}$.

Media pendingin air yang ada pada tabung kondensor disirkulasikan melalui pompa air dengan debit sebesar $3000 \mathrm{~L} / \mathrm{jam}$ dan daya 70 watt. Selain itu tabung kondensor juga ditempatkan di atas penyangga yang memiliki ketinggian $94 \mathrm{~cm}$. Hal ini bertujuan agar aliran asap yang terkondensasi dapat mengalir secara gravitasi untuk menuju ke tabung berikutnya. Gambar desain dan realisasi tabung kondensor dapat dilihat pada Gambar 5.
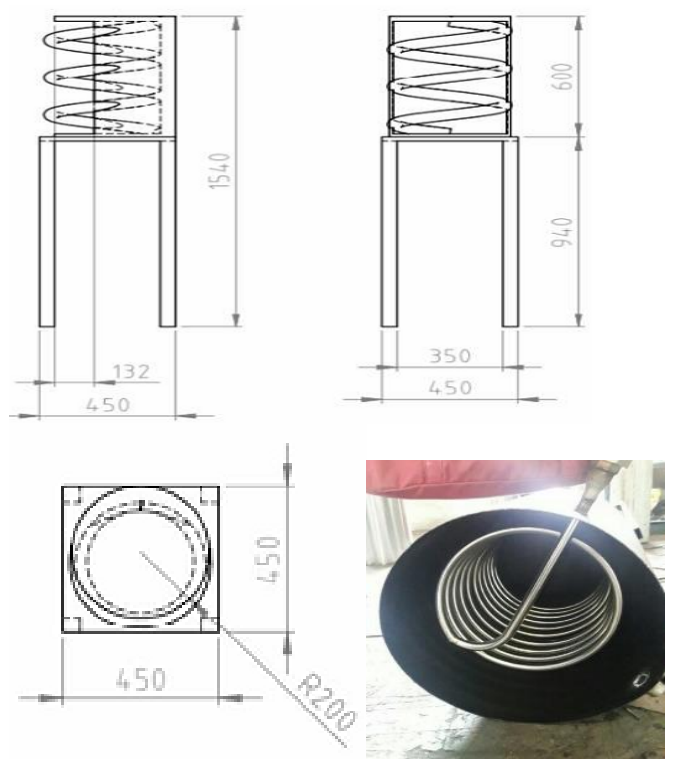

Gambar 5. Tabung Kondensor

\section{Tabung Filtrasi}

Media filtrasi berbentuk tabung dengan diameter $15 \mathrm{~cm}$ dan tinggi $70 \mathrm{~cm}$, dengan bagian bawah terdapat keran untuk mengeluarkan hasil asap cair. Tabung filtrasi dibagi mejadi dua bagian bertingkat dengan masing masing tingkat memiliki ketinggian $20 \mathrm{~cm}$. Tingkat pertama digunakan untuk penempatan zeolit dan tingkatan kedua digunakan untuk penempatan arang aktif. Gambar desain dan realisasi tabung filtrasi dapat dilihat pada Gambar 6.

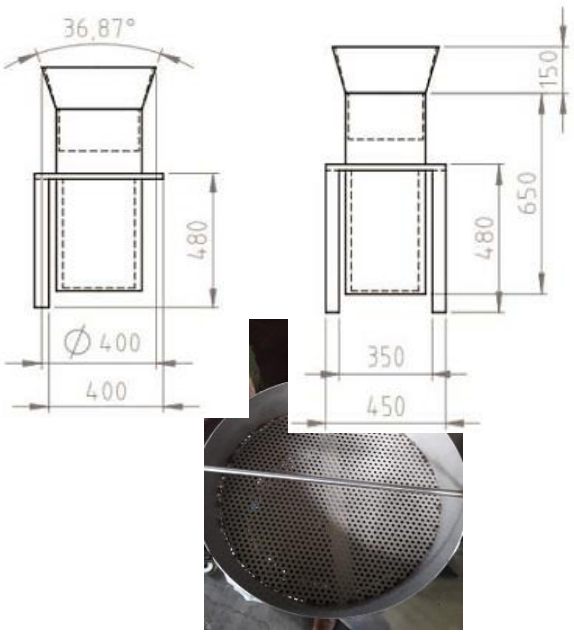

Gambar 6. Tabung Filtrasi

\section{Rangkaian Mesin}

Setelah semua bagian selesai dibuat maka selanjutnya adalah menyatukan bagian bagian menjadi sebuah rangkaian mesin pembuat asap cair dari tempurung kelapa. Rangkaian mesin pembuat asap cair memiliki dimensi total panjang 132 $\mathrm{cm}$ dengan lebar $100 \mathrm{~cm}$ dan tinggi 145 $\mathrm{cm}$. Gambar rangkaian mesin dapat dilihat pada Gambar 7.

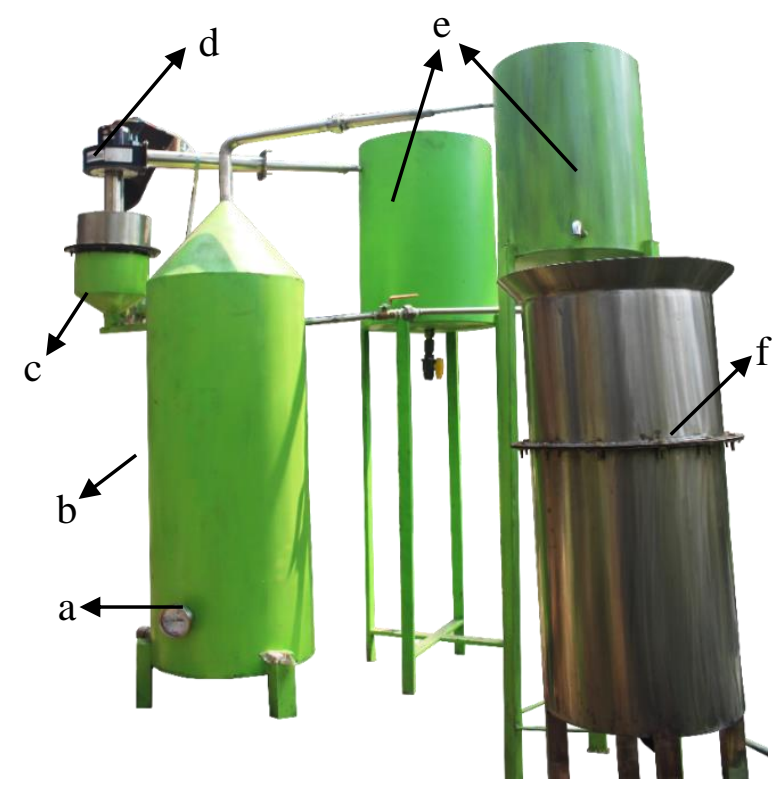

Gambar 7. Rangkaian Mesin Pembuat Asap Cair 
Keterangan gambar:

a. Termometer Analog

b. Tabung Distilasi

c. Cyclone Separator

d. Blower hisap

e. Tabung Kondensor

f. Tabung Filtrasi

\section{Volume Asap Cair}

Asap cair dari tempurung kelapa yang dihasilkan menggunakan mesin berbasis cyclone-redistillation memiliki volume total 2 kali lipat jika dibandingkan dengan metode konvensional (distilasi biasa) pada UKM pembuat asap cair dari tempurung kelapa. Jumlah bahan baku tempurung kelapa yang sama (3000 Kg), pada metode konvensional hanya mampu menghasilkan 50 Liter asap cair, sedangkan menggunakan teknologi cyclone-redistillation dapat menghasilkan 100 Liter asap cair. Berdasarkan jumlah volume asap cair tersebut, kemudian diteruskan ke proses selanjutnya untuk mendapatkan grade A, B dan C. Volume asap cair setiap grade yang dihasilkan ditunjukkan pada Gambar 8.

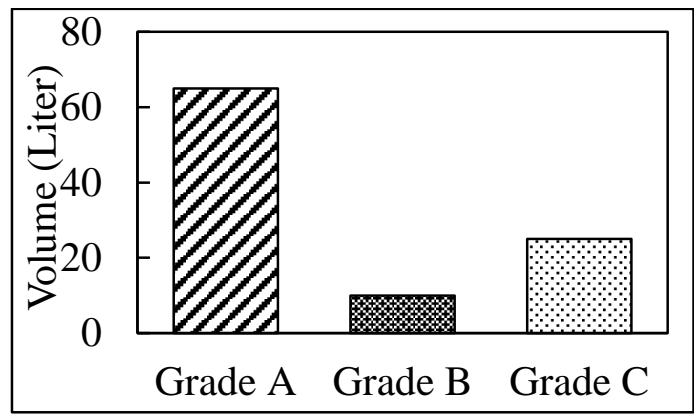

Gambar 8. Volume setiap grade asap cair yang dihasilkan menggunakan teknologi cyclone-redistillation

Berdasarkan Gambar 8, volume asap cair grade A (65 Liter) memiliki nilai yang paling besar dibanding dengan volume grade $\mathrm{B}(10$ Liter) dan grade $\mathrm{C}$ (25 Liter). Hal ini dikarenakan teknologi cyclone-redistillation yang diterapkan pada mesin memang diperuntukkan untuk menghasilkan asap cair grade A. Waktu yang dibutuhkan untuk menghasilkan asap cair grade A yaitu kurang lebih 48 jam.

Oleh karena itu aplikasi mesin pembuat asap cair dari tempurung kelapa berbasis teknologi cyclone-redistillation ini dapat mempersingkat waktu produksi asap cair dari 120 jam (teknologi konvensional) menjadi 48 jam. Kenampakan visual hasil asap cair grade $\mathrm{A}, \mathrm{B}$ dan $\mathrm{C}$ yang diperoleh menggunakan teknologi cyclone-redistillation ditunjukkan pada Gambar 9.

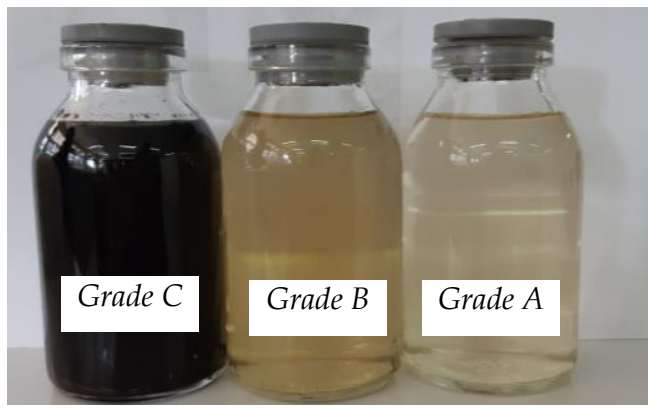

Gambar 9. Perbedaan asap cair yang dihasilkan dengan teknologi cycloneredistillation

Berdasarkan Gambar 9, terdapat perbedaan kenampakan visal yang cukup signifikan antara ketiga grade asap cair yang dihasilkan dengan teknologi cyclone-redistillation. Asap cair grade C atau grade 3 memiliki warna yang sangat gelap dan memiliki aroma menyengat. Hal tersebut dikarenakan banyaknya kandungan tar yang bersifat karsinogenik di dalam asap cair, sehingga aplikasi asap cair grade $\mathrm{C}$ atau grade 3 ini yaitu sebagai koagulan pengolahan karet dan pengawet kayu agar tahan terhadap rayap (Fauzan \& Ikhwanus, 2017).

Asap cair grade $\mathrm{B}$ atau grade 2 memiliki warna yang lebih terang daripada grade $\mathrm{C}$. Warna asap cair yang lebih terang ini disebabkan karena proses penguapan pada suhu $95^{\circ} \mathrm{C}$ pada proses redistilasi, sehingga senyawa yang tidak diinginkan seperti tar dan hidrokarbon polisikis aromatik dapat dipisahkan. Asap cair grade A memiliki warna yang paling 
jernih daripada kedua asap cair lainnya dan memiliki aroma yang netral. Hal ini dikarenakan asap cair disaring dengan zeolit untuk mendapatkan asap cair yang benar-benar bebas dari zat berbahaya seperti benzopyrene, sedangkan filtrasi dengan karbon aktif bertujuan untuk mendapatkan filtrat asap cair dengan bau asap yang ringan dan tidak menyengat (Fauzan \& Ikhwanus, 2017).

Asap cair grade A atau grade 1 merupakan asap cair yang paling bagus kualitasnya dan tidak mengandung senyawa yang berbahaya. Oleh karena itu, asap cair ini dapat digunakan sebagai pengawet pangan alami pengganti boraks yang dapat diterapkan seperti pada produk bakso, mie, bumbu-bumbu dan produk pangan lainnya. Selain itu karakteristik asap yang memiliki warna bening, rasa sedikit asam dan aroma netral (Fauzan \& Ikhwanus, 2017).

Namun demikian untuk mengetahui performansi mesin lebih lanjut terhadap asap cair yang dihasilkan, perlu dilakukan pengujian lebih lanjut terhadap kualitas asap cair baik dari parameter fisik maupun kimia. Hal ini dikarenakan kualitas asap cair ditentukan oleh kandungan fenol dan tingkat keasaman karena keduanya memiliki peran besar sebagai anti bakteri. Semakin tinggi kandungan fenol dan tingkat keasamannya, maka semakin tinggi kemampuan asap cair tersebut dalam mencegah timbulnya mikroorganisme (Budijanto dkk., 2008). Selain itu diperlukan penelitian lanjut untuk mengontrol beberapa paramater pada proses pirolisis tempurung kelapa yang digabungkan dengan teknologi cycloneredistillation.

\section{KESIMPULAN}

Mesin pembuat asap cair dari tempurung kelapa menggunakan teknologi cyclone-redistillation telah dibuat sesuai spesifikasi rancangan struktural dan rancangan fungsional. Dimensi keseluruhan mesin meliputi panjang $132 \mathrm{~cm}$, lebar $100 \mathrm{~cm}$ dan tinggi $145 \mathrm{~cm}$. Mesin mampu menghasilkan volume total asap cair 100 Liter yang dapat diklasifikasikan untuk grade $\mathrm{A}, \mathrm{B}$ dan $\mathrm{C}$ masing-masing $65 \mathrm{~L}, 10 \mathrm{~L}$, dan 25 L. Selain itu, waktu proses pembuatan asap cair lebih singkat yaitu dari 120 jam menjadi 48 jam jika dibandingkan dengan metode konvensional pada UKM pembuat asap cair. Oleh karena itu, teknologi cyclone-redistillation ini memiliki potensi yang besar untuk diterapkan pada UKM penghasil asap cair di Indonesia dalam meningkatkan produktivitas dan kualitas asap cair dari limbah tempurung kelapa.

\section{DAFTAR PUSTAKA}

Badan Pusat Statistik. (2016). Produksi Tanaman Perkebunan menurut Kabupaten/Kota dan Jenis Tanaman di Provinsi Jawa Timur, 2016 (Ton). Diakses dari https://jatim.bps.go.id/statictable/ 2017/06/19/570/produksi-tanamanperkebunan-menurut-kabupatenkota- dan-jenis-tanaman-diprovinsi-jawa-timur-ton-2016.html

Budijanto, S., Hasbullah R., Prabawati, S., Setyadjit, Sukarno, Zuraida, I. (2008). Identifikasi dan Uji Keamanan Asap Cair Tempurung Kelapa untuk Produk Pangan. J. Pascapanen, 5 (1), 32-40.

Ditjenbun. (2017). Statistik Perkebunan Indonesia 2015-2017 Kelapa. Available at http://ditjenbun.pertanian.go.id/tinymc puk/gambar/file/statistik/2017/Kelapa2015-2017.pdf

Fauzan dan Ikhwanus, M. (2017). Pemurnian Asap Cair Tempurung Kelapa Melalui Distilasi dan 
Filtrasi Menggunakan Zeolit dan Arang Aktif. Prosiding Semnastek: Fakultas Teknik Universitas Muhammadiyah Jakarta, 1-5.

Kailaku, S.I., Syakir, M., Mulyawanti I., \& Syah A. (2017). Antimicrobial Activity of Coconut Shell Liquid Smoke. IOP Conf. Ser.: Mater. Sci. Eng. 206. doi:10.1088/1757$899 X / 206 / 1 / 012050$

Pranata J. 2007. Pemanfaatan Sabut dan Tempurung Kelapa serta Cangkang Sawit untuk Pembuatan Asap Cair sebagai Pengawet Makanan Alami. Skripsi. Teknik Kimia Universitas Malikussaleh. Lhoksumawe.
Sakin A., Karagoz I., Ergul M., Demirtas U dan Savas F.H. (2017). An investigation into the use of a cyclone separator in the intake air system and its influence on the engine performance. Proceedings the Institution of Mechanical Engineers, Part D: Journal of Automobile Engineering, 232 (5), 667-678.

Zuraida, I., Sukarno, Budijanto, S. (2011). Antibacterial Activity of Coconut Shell Liquid Smoke (CSLS) and its Application on Fish Ball Preservation. International Food Research Journal, 1 (18), 405-410. 